
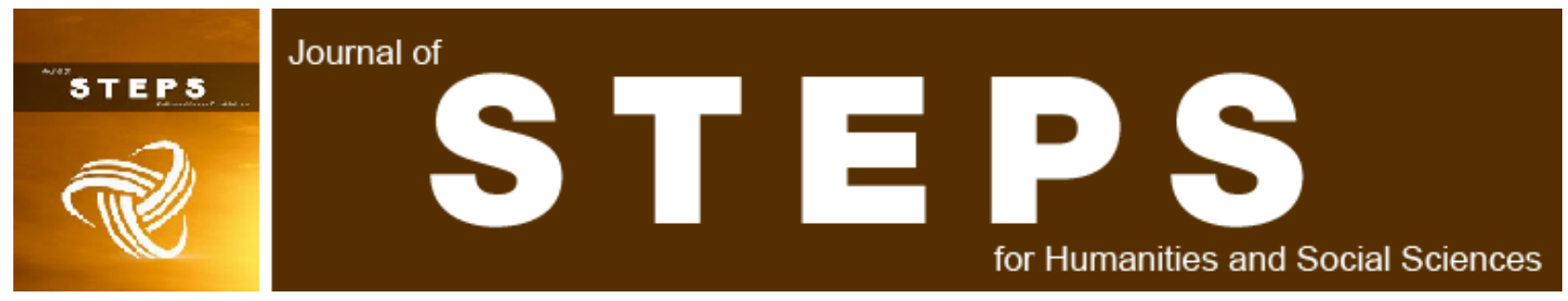

Volume 1 | Issue 1

Article 6

\title{
The effect of the phenomenon of housing transition and housing fragmentation on the housing need for the cities of Al Hayy and Al Azizia
}

Sabeeh Farhan

Wasit University, Iraq

Shakir Alzamly

Wasit University, Iraq

Ayat Allaami

Wasit University, Iraq, Aylul_2021@gmail.com

Follow this and additional works at: https://www.steps-journal.com/jshss

Part of the Arts and Humanities Commons

\section{Recommended Citation}

Farhan, Sabeeh; Alzamly, Shakir; and Allaami, Ayat (2022) "The effect of the phenomenon of housing transition and housing fragmentation on the housing need for the cities of Al Hayy and Al Azizia," Journal of STEPS for Humanities and Social Sciences: Vol. 1 : Iss. 1 , Article 6.

Available at: https://doi.org/10.55384/2790-4237.1007

This Original Study is brought to you for free and open access by Journal of STEPS for Humanities and Social Sciences (STEPS). It has been accepted for inclusion in Journal of STEPS for Humanities and Social Sciences by an authorized editor of Journal of STEPS for Humanities and Social Sciences (STEPS). 


\section{اثر ظاهرة الانتقال السكني وتجزئة المساكن على الحاجة السكنية لمدينتي الحي والعزيزية}

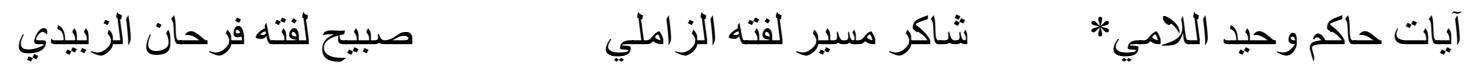

المستخلص

رافقت مشكلة السكن ظاهرة تجزئة الوحدات السكنية الى اجز اء صغيرة واستعمالها لأغر اض مختلفة تخدم

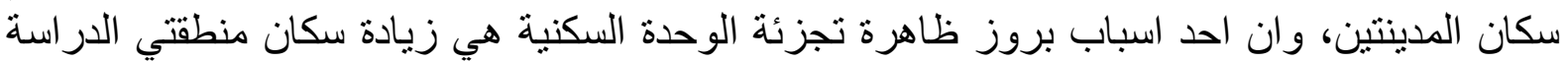
وبسبب الهجرة من الاقضية والمحافظات، ولهذه الظاهرة اثار سلبية منها التأثير على البنى التحتية و التلوث البيئي والضوضائي واختناق فضاءات المحلة بسبب الابنية وزيادة عدد السكان واختلاف المستويات

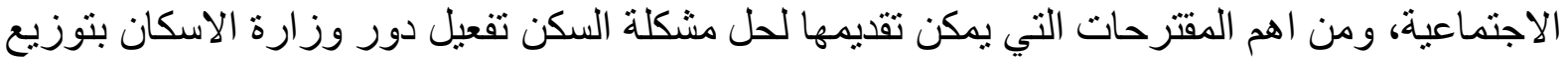
قطع الار اضي ليتمكن سكان المدينة بناء دور هم مما يخلصهم من ارتفاع معدلات الاتهن الايجار ات، كذلك تفعيل

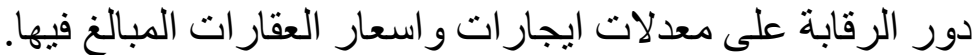

كلمات مفتاحية: : الانتقال السكني، تجزئة المساكن، الحي والعزيزية. 


\title{
The status of Arab urban centers in the geographical heritage
}

*Ayat Allaami, College of Education for Human Sciences, Wasit University, Iraq.

Sabeeh Farhan, College of Education for Human Sciences, Wasit University, Iraq.

Shakir Alzamly, College of Education for Human Sciences, Wasit University, Iraq.

\begin{abstract}
The housing problem has accompanied the phenomenon of splitting housing units into small parts and using them for various purposes that serve the residents of the two cities, and one of the reasons for the emergence of the phenomenon of fragmentation of the housing unit is the increase in the population of the two study areas and because of migration from districts and governorates, and this phenomenon has negative effects, including the impact on infrastructure, environmental and noise pollution and suffocation of spaces The locality, due to the buildings, the increase in the population and the different social levels, and among the most important proposals that can be made to solve the housing problem is to activate the role of the Ministry of Housing by distributing plots of land so that city residents can build their role, which saves them from high rental rates, as well as activating the role of monitoring the rates of rentals and exaggerated real estate prices.
\end{abstract}

Keywords: housing transition, housing fragmentation, Al Hayy and Al Azizia. 


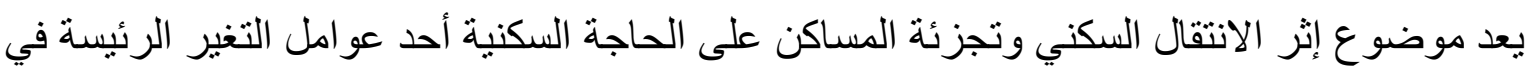

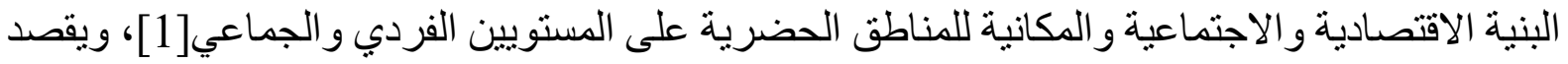

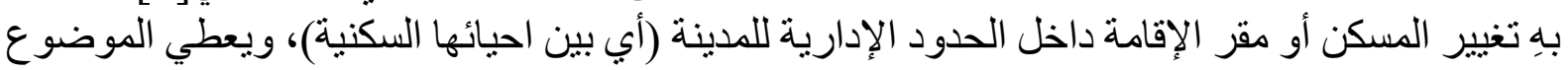

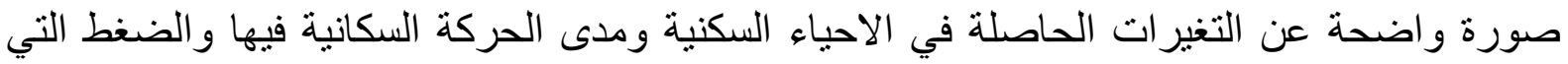

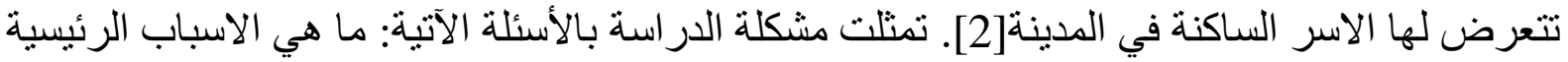

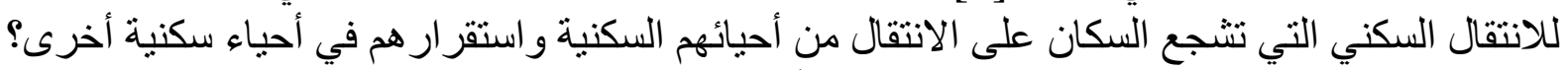

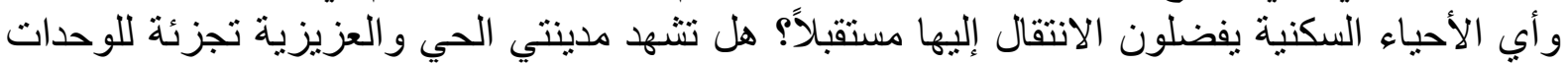

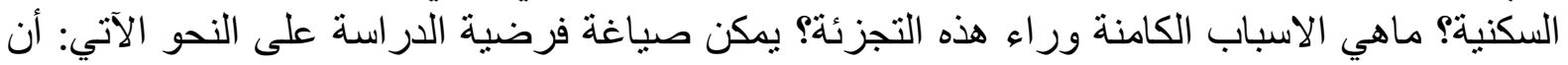

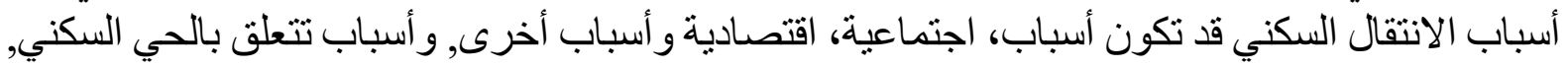

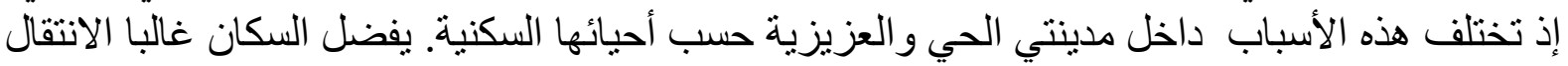

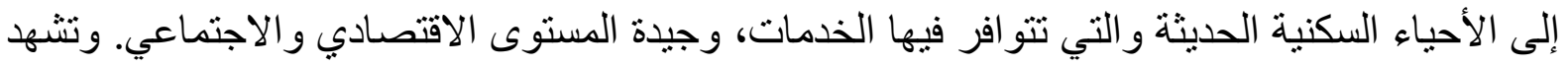

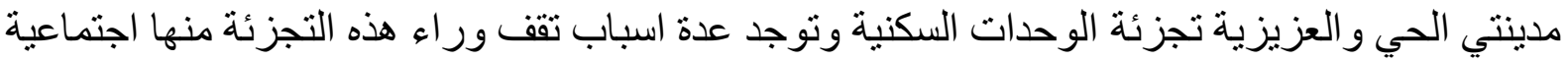

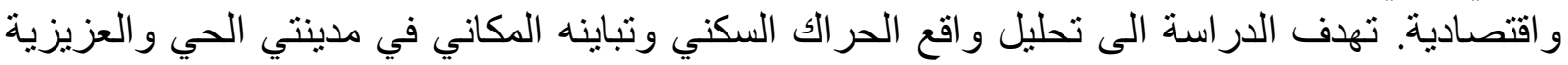

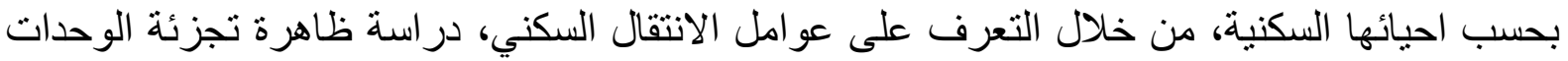

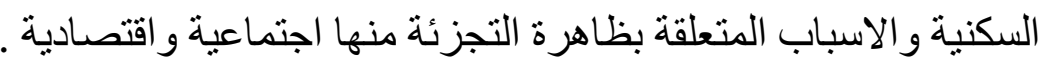

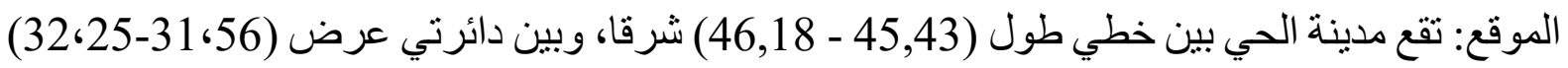

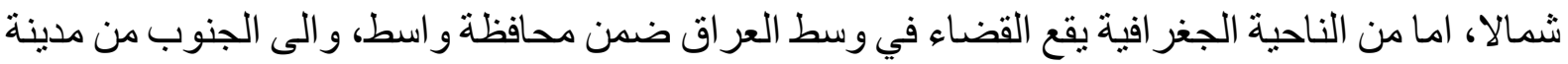

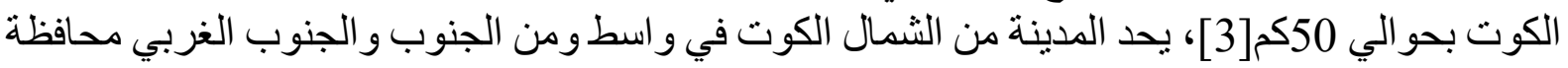

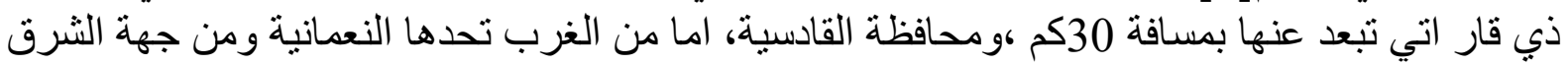

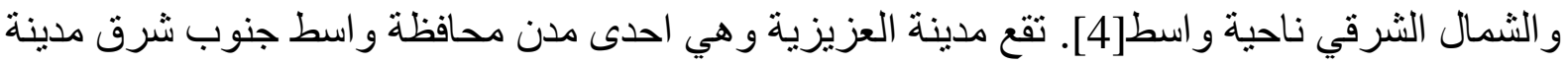

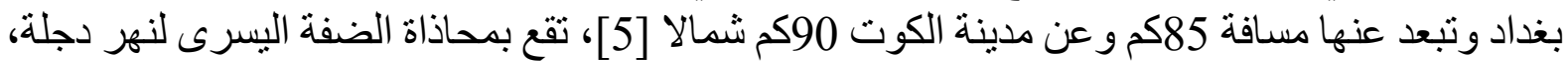

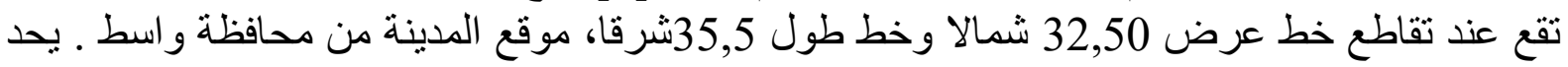

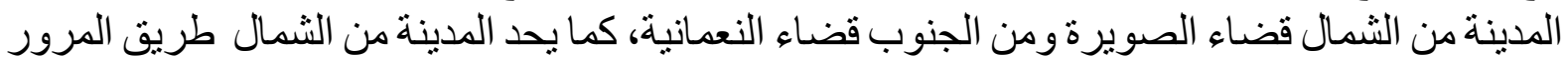

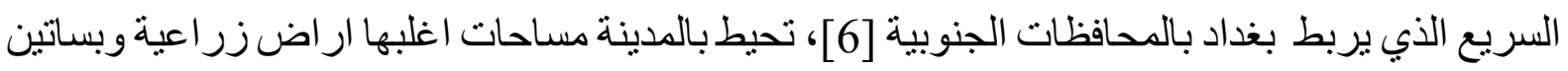

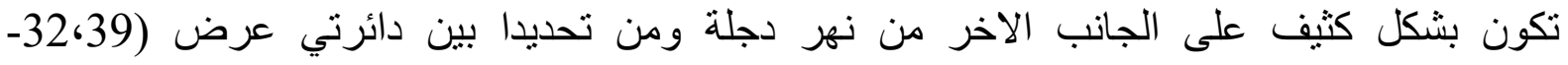

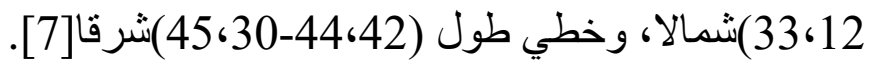




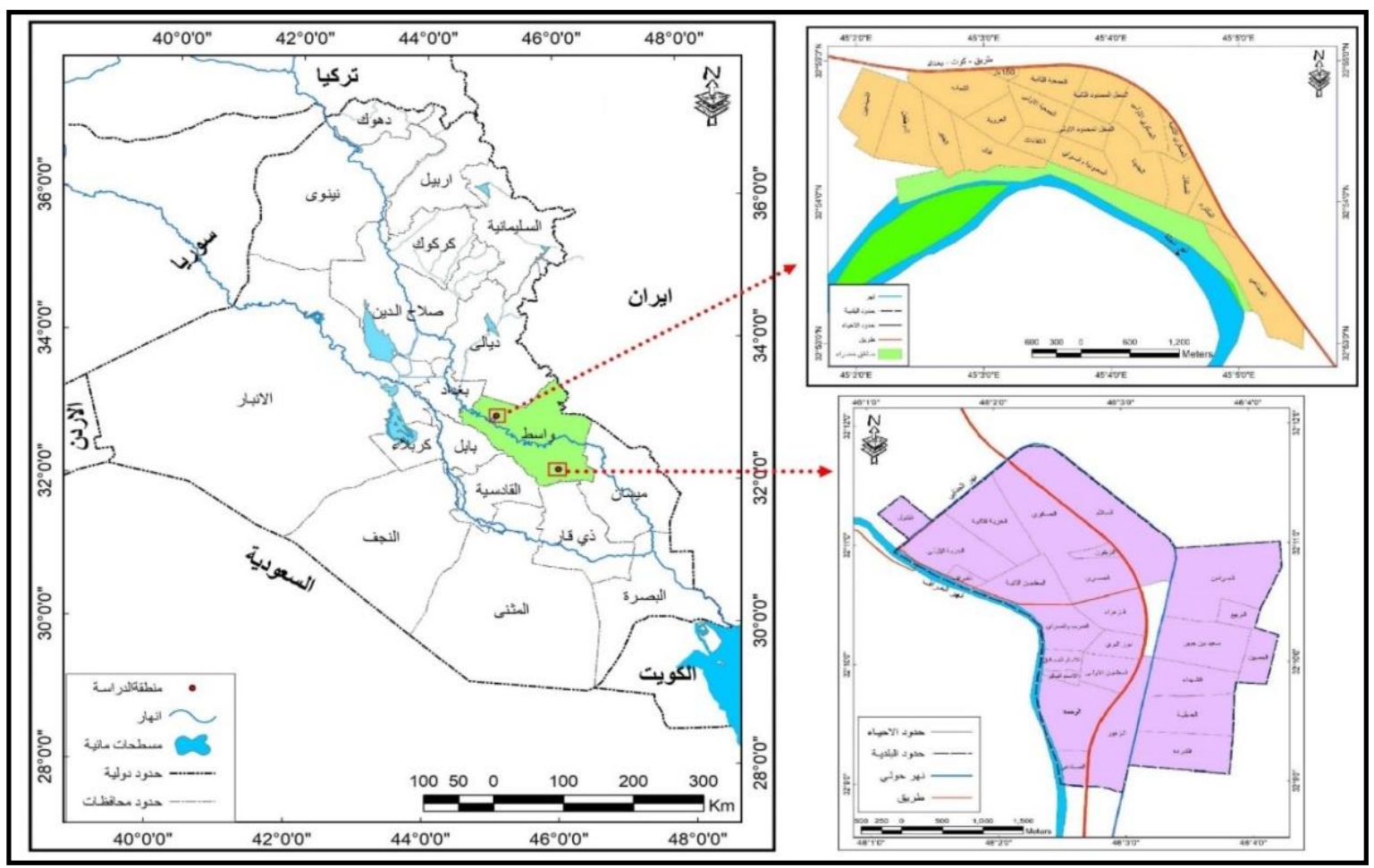

خريطة . 1. موقع مدينتي الحي و العزيزية بالنسبة لمحافظة واسط لعام 2020 ـالمصدر : وزارة الموارد المائية الهيئة

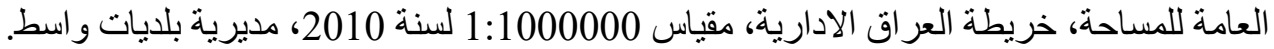

\section{تغيير محل السكن}

توجد عدة اسباب تدعو الى الانتقال من حي سكني الى اخر تتو افر فيه الخدمات المجتمعية العامة، كما

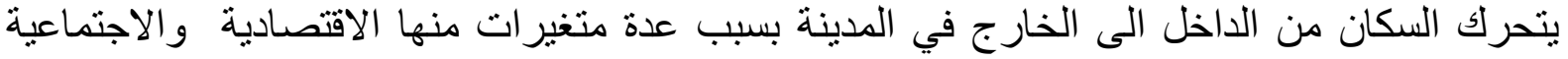

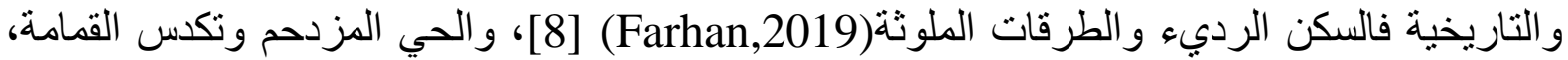

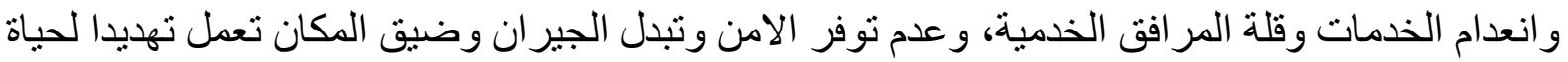

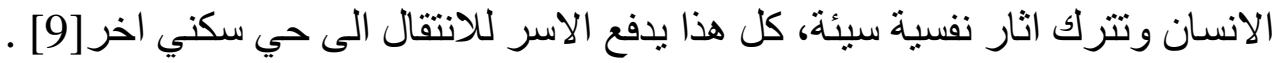

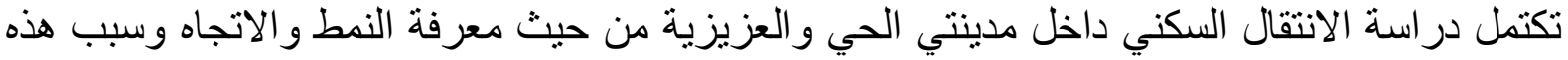

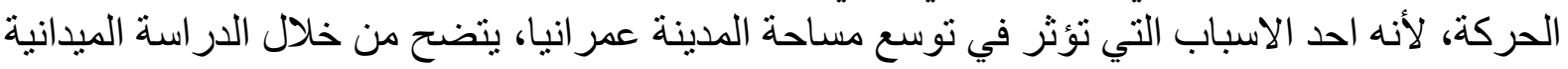

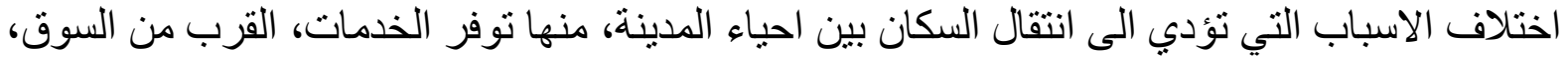

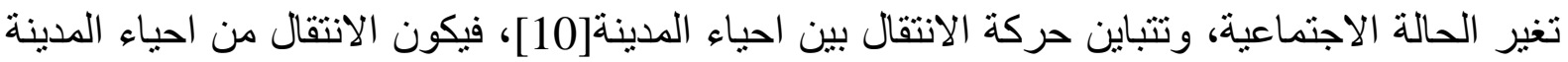

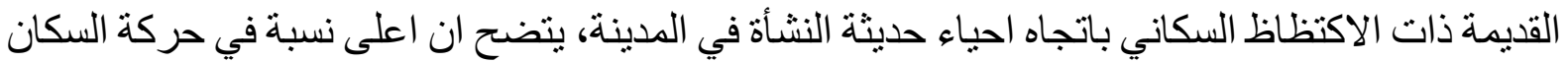

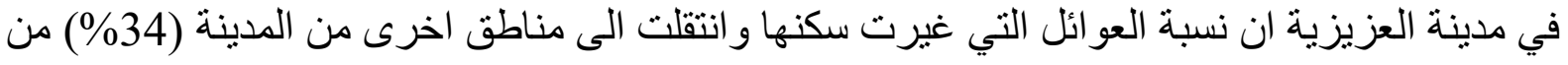

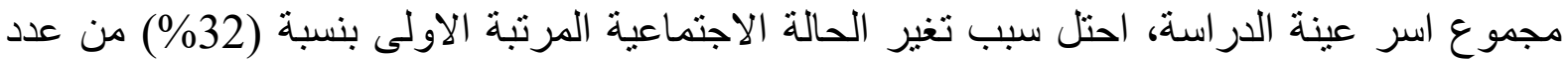

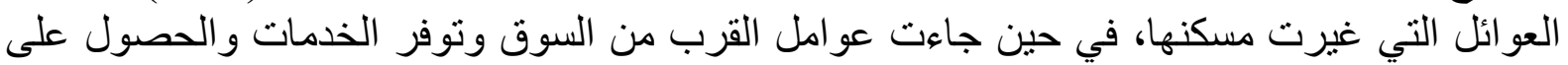

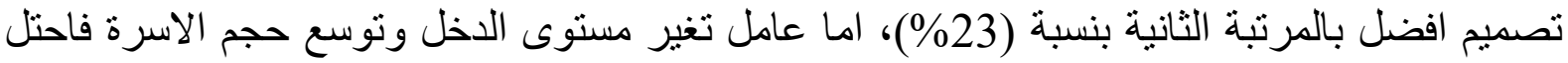
المرتبة الثالثة بنسبة (18\%)، و(15\%) لعامل بعد المسكن عن الاهل وارتفاع مستوى الايجار يشغل المرتبة الر ابعة، احتل مشكلات مع الجير ان المرتبة الاخيرة بنسبة (12\%) (12\%)

يلاحظ بأن الانتقال بين الأحياء يمثل طلباً على المساكن سواء الثراء او الايجار وهذا يؤدي إلى زيادة أسعار ها التي تنعكس على الوضع الاقتصادي للفرد المؤجر أو الذي ير غب الأبر بشر اء بيتاً خاصاً لله. 
جدول (1) :اسباب تغير محل السكن في مدينتي الحي و العزيزية لعام 2020, المصدر: استمارة الاستبيان، المحور الثالث الخاص بتغيير محل السكن، السؤال(1).

\begin{tabular}{|c|c|c|c|}
\hline \multicolumn{2}{|r|}{ الحي } & \multicolumn{2}{|r|}{ العزيزية } \\
\hline النسبة & الاسباب & النسبة & الاسباب \\
\hline$\% 25$ & تغير الحالة الاجتماعية & $\% 32$ & تغير الحالة الاجتماعية \\
\hline$\% 29$ & الحصول على تصميم افضل السوق & $\% 23$ & 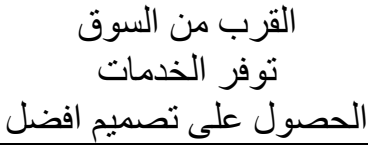 \\
\hline$\% 21$ & ارتفاع مستوى الايجار & $\% 18$ & زيادة حجم الاسرة الدخل \\
\hline$\% 14$ & بعد المسكن عن الاهل & $\% 15$ & ارتفاع مستوى الايجن عن الاهل \\
\hline$\% 11$ & مشكلات مع الجيران & $\% 12$ & مشكلات مع الجيران \\
\hline
\end{tabular}

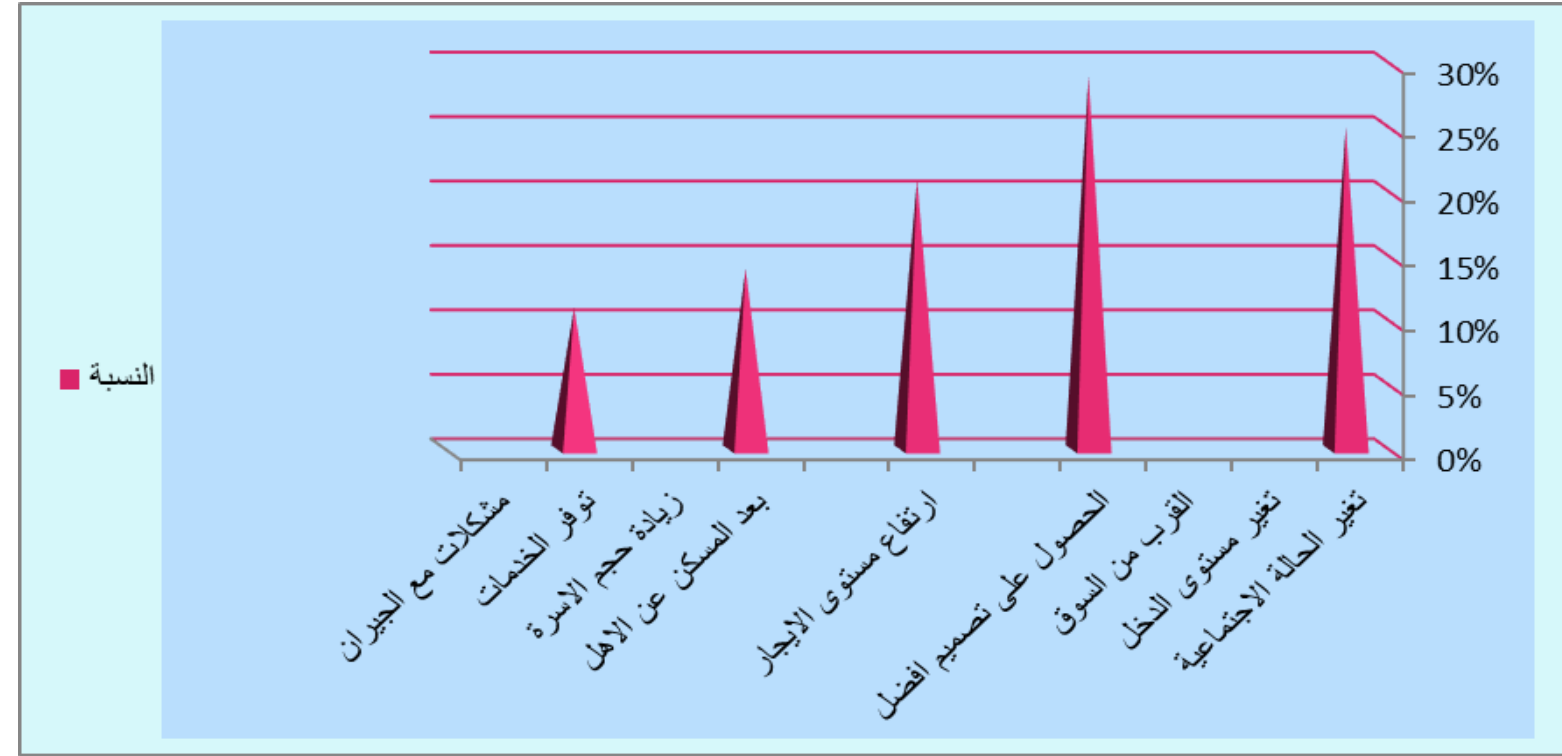

شكل (1) :اسباب تغير محل السكن في مدية العزيزية لعام 2020, المصدر: جدول (1).

اختلفت الاسباب التي ادت الى انتقال الاسر من حي سكني الى اخر في مدينة الحي، ومن خلال الدراسة

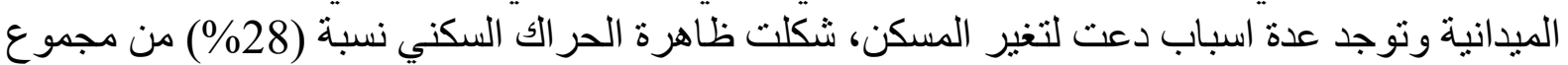

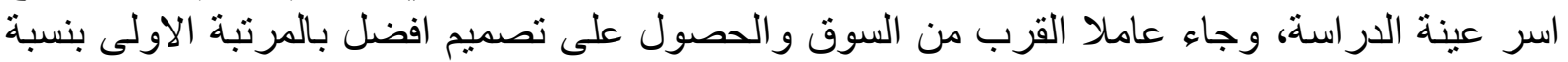

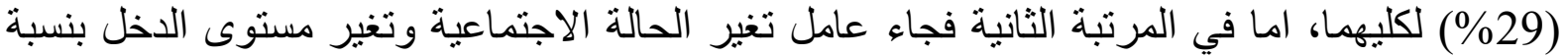

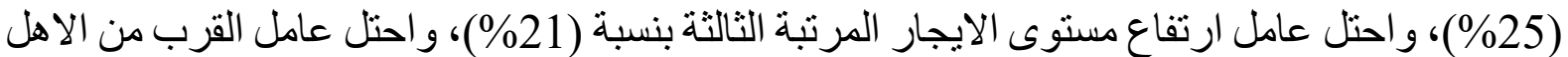

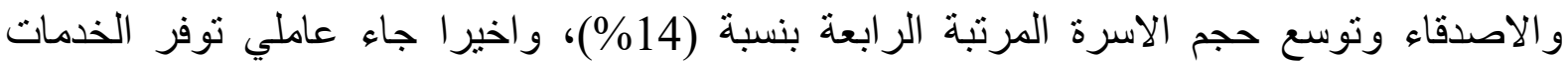

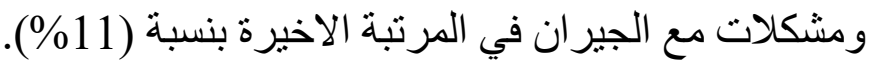

ان انتقال الاسر من المناطق الطاردة الى المناطق الجاذبة لتحسن الاوضاع الاقتصادية و المعيشية سبب

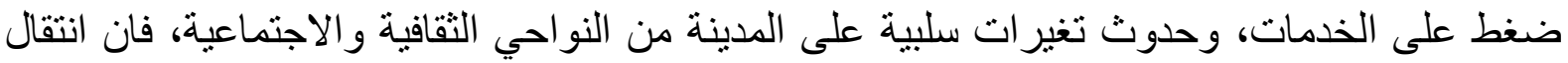

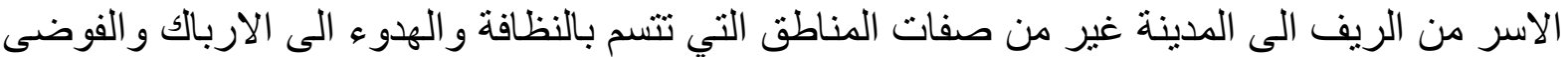

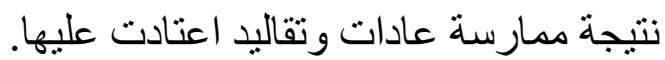




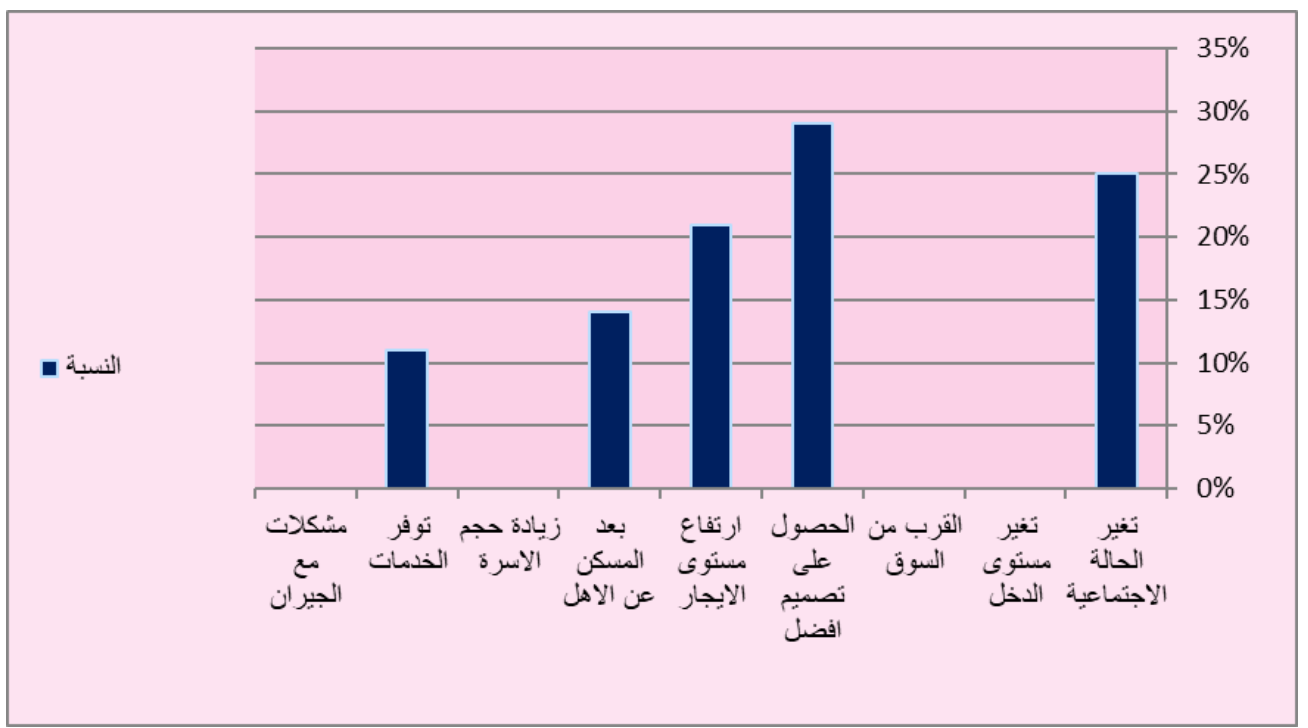

شكل .2. اسباب تغير محل السكن في مدينة الحي لعام 2020, المصدر: جدول (1).

\section{رغبة الأسر في الانتقال السكني مستقبلا في مدينتي الحي والعزيزية}

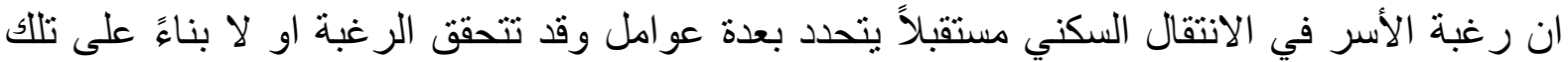

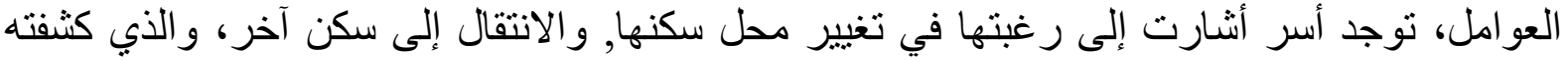

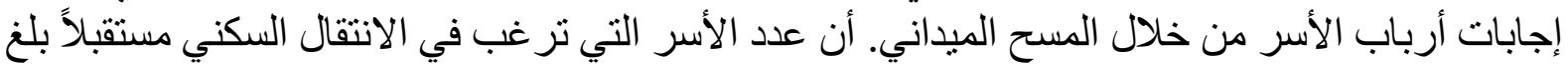
(167) أسرة أي ما يعادل (44.6\%)من مجموع الأسر في مدينة الحي، وفي مدينة العزيزية بلغ عدد الاسر الاسبر

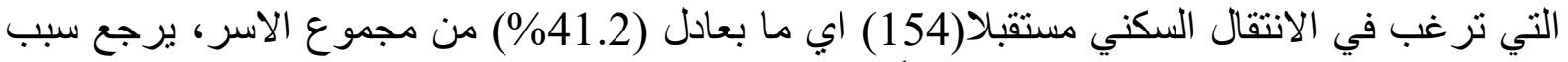

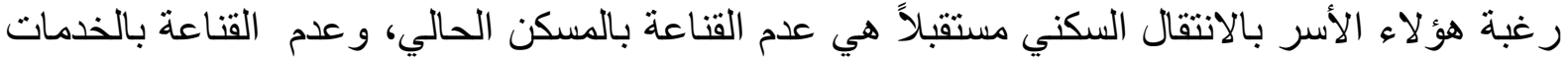

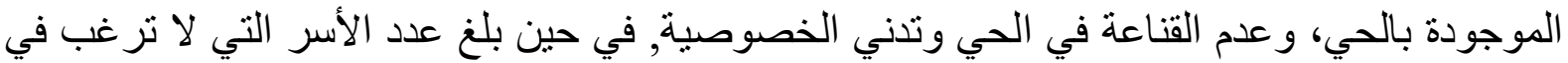

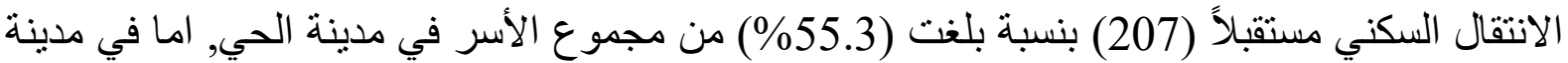

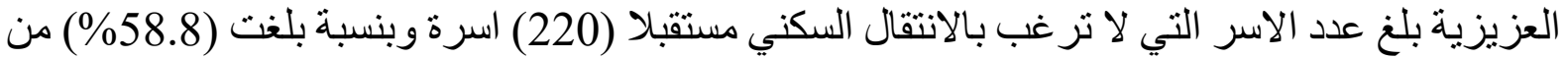
مجموع الاسر، يرجع ذلك للعدة اسباب تأثر أغلب الأسر التي لا تر غب في في الانتقال بالرو ابط الاجتماعية و الاقتصادية كوجود( الأهل و الأقارب و الأصدقاء) في الحي ومعرفة أصحاب المتاجر و المحلات و وأماكن

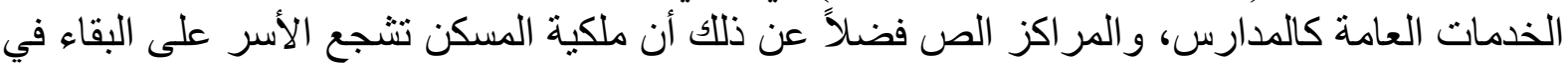

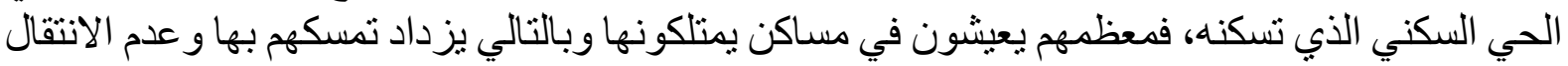

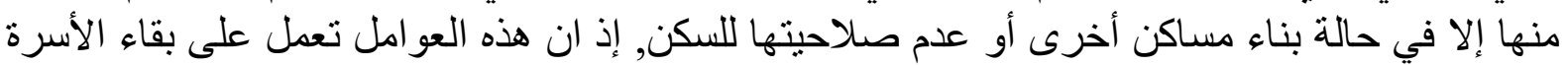

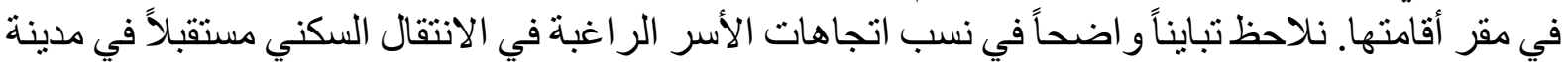

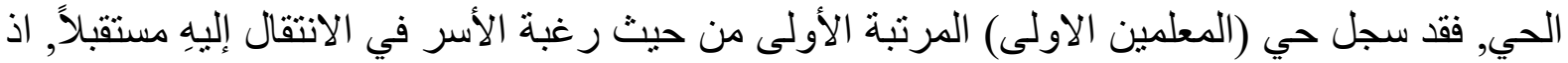

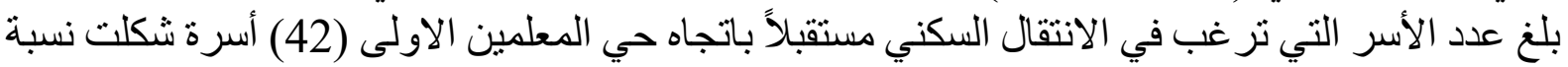

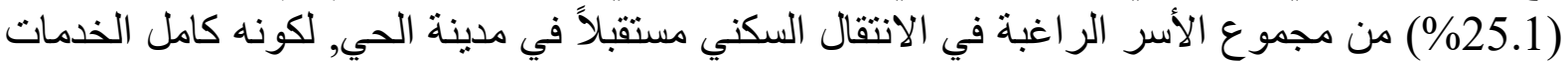

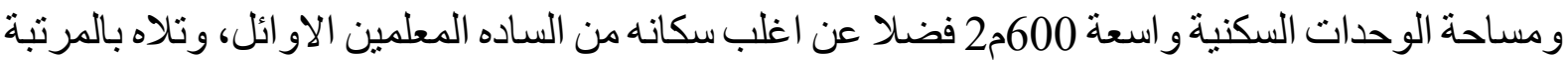

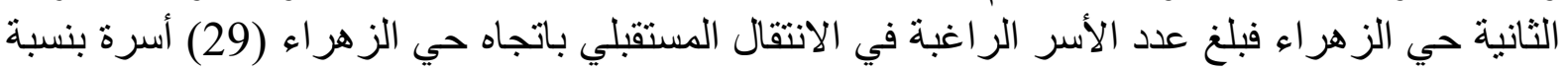

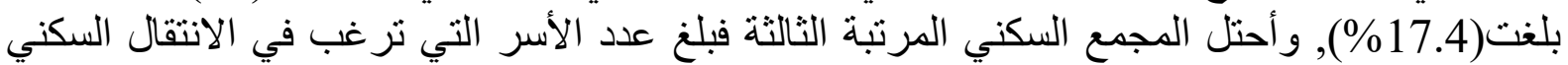
مستقبلاً إلى المجمع السكني (15) أسرة بنسبة بلغت (8.9\%), و احتل حي الكر ادة و العصري المرتبة فئة

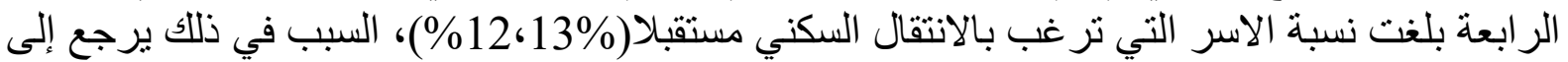

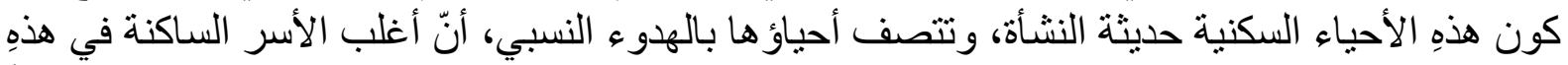

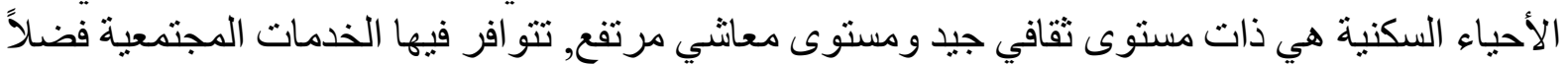

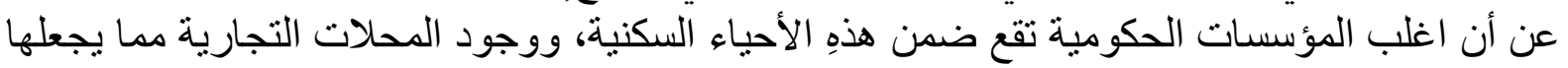


مناطق جذب من قبل الأسر للانتقال و السكن فيها، وتراوحت بقية الأحباء السكنية بين النسب التي تم ذكر ها،

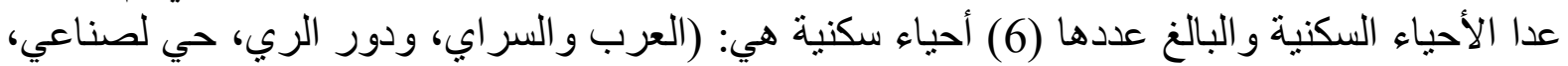

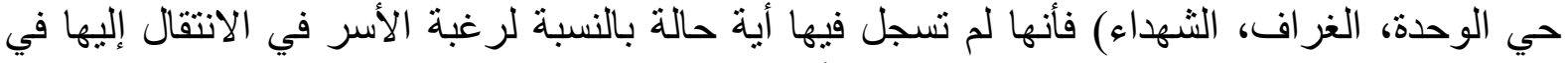

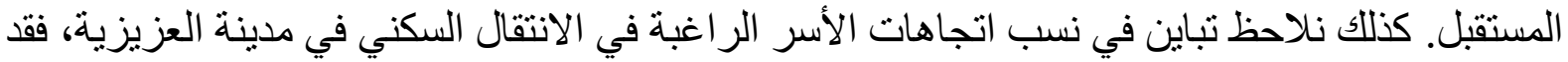

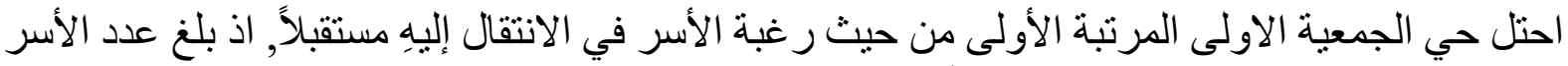

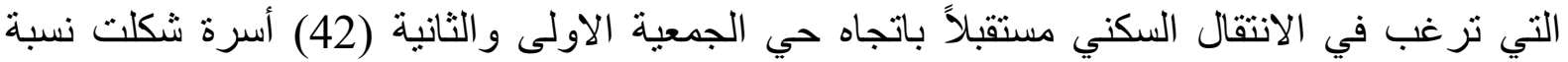

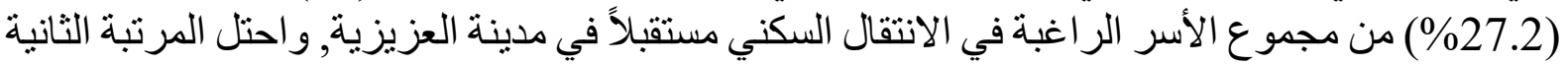

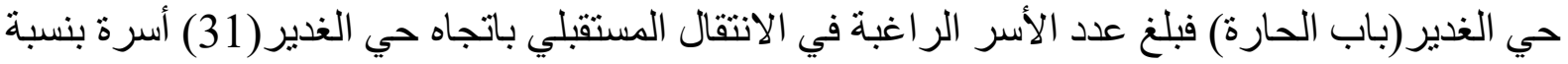

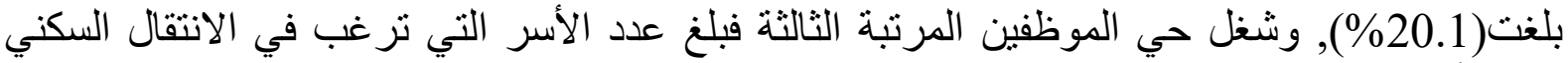

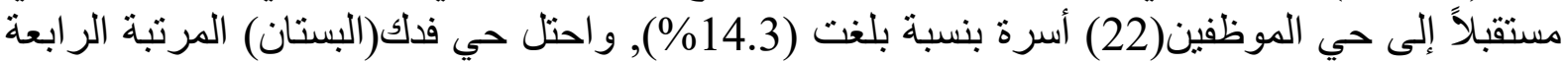

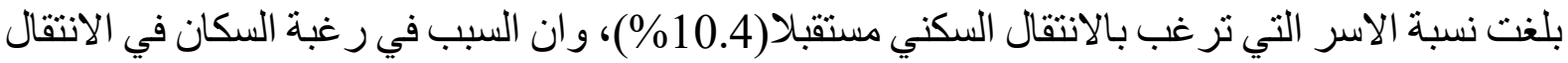

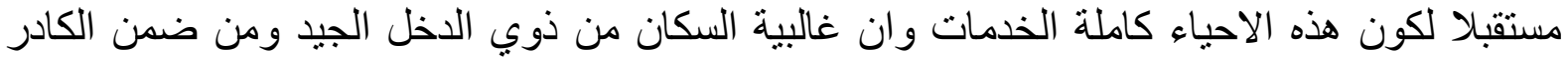

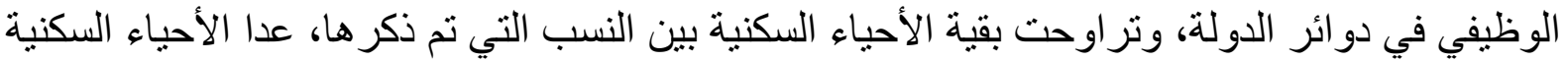

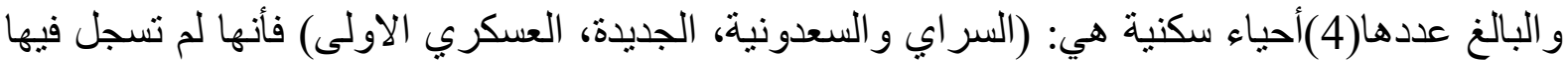
أية حالة بالنسبة لر غبة الأسر في الانتقال إليها في المستقبل. جدول.2 اتجاهات الاسر الراغبة في الانتقال السكني مستقبلا في مدينتي الحي و العزيزية. المصدر: استمارة الاستيبان،

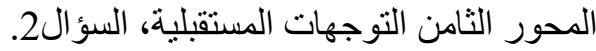

\begin{tabular}{|c|c|c|c|c|c|c|}
\hline \multicolumn{3}{|c|}{ مدينة العزيزية } & \multicolumn{4}{|c|}{ مدينة الحي } \\
\hline \multicolumn{2}{|c|}{ 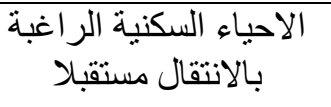 } & \multirow[b]{2}{*}{ الاحياء السكنية } & \multicolumn{2}{|c|}{ الاحياء السكنية الر اغبة } & \multirow{2}{*}{ الاحياء السكنية } & \multirow[t]{2}{*}{$ت$} \\
\hline$\%$ & العدد & & $\%$ & العدد العد & & \\
\hline 20.1 & 31 & الغدير & 4.8 & 8 & العسكري & 1 \\
\hline 2.6 & 4 & الكفاءات & 6.6 & 11 & سعيد بن جبير & 2 \\
\hline 0 & 0 & السعدونية و السر اي & 0 & 0 & السر اي و العرب & 3 \\
\hline 4 & 6 & الدخل المحدود الاولى & 0 & 0 & حي الوحدة & 4 \\
\hline 4.5 & 7 & الدخل المحدود الثانية & 7.8 & 13 & العصري & 5 \\
\hline \multirow[t]{2}{*}{27.2} & 42 & الجمعية الاولى و الثانية & 3.6 & 6 & الحرية الاولى & 6 \\
\hline & & & 3 & 5 & الحرية الثانية & 7 \\
\hline 2.6 & 4 & حي ال150 & 0 & 0 & الغر اف & 8 \\
\hline 3.2 & 5 & التشباب & 25.1 & 42 & المعلمين الاولى & 9 \\
\hline 0.6 & 1 & العروبة & 2.4 & 4 & المعلمين الثانية & 10 \\
\hline 10.4 & 16 & فذك & 0 & 0 & الثهداء & 11 \\
\hline 0 & 0 & العسكري الاولى & 17.4 & 29 & الز هر اء & 12 \\
\hline 0.6 & 1 & العسكري الثانية & 1.8 & 3 & الباقر & 13 \\
\hline 2 & 3 & المستقبل & 1.2 & 2 & الصـادق & 14 \\
\hline 1.3 & 2 & المكارم & 0.6 & 1 & الجو ادين & 15 \\
\hline 2.6 & 4 & الاسكان الصناعي & 0 & 0 & حي الصناعي & 16 \\
\hline 0 & 0 & الجديدة & 0.6 & 1 & الز هور & 17 \\
\hline 14.3 & 22 & الموظفين & 0.6 & 1 & الربيع & 18 \\
\hline \multirow[t]{6}{*}{4} & 6 & السياسبين & 0 & 0 & دور الري & 19 \\
\hline & & & 2.4 & 4 & حي الحسين & 20 \\
\hline & & & 7.2 & 12 & الكر ادة & 21 \\
\hline & & & 3 & 5 & السلام & 22 \\
\hline & & & 1.2 & 2 & الجميلية & 23 \\
\hline & & & 1.8 & 3 & الزيتون & 24 \\
\hline
\end{tabular}




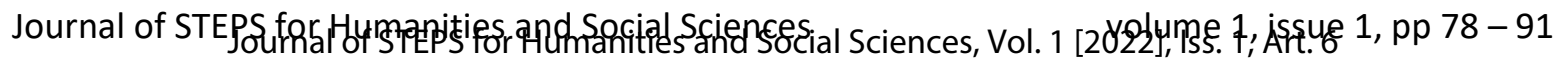

\begin{tabular}{|c|c|c|c|c|c|c|}
\hline \multicolumn{3}{|c|}{ مدينة العزيزية } & \multicolumn{4}{|c|}{ مدينة الحي } \\
\hline \multicolumn{2}{|c|}{ بالاحياء السكنية الر اغبة } & \multirow{2}{*}{ الاحياء السكنية } & \multicolumn{2}{|c|}{ الاحياء السكنية الر اغبة } & \multirow{2}{*}{ الاحياء السكنية } & \multirow[t]{2}{*}{ ت } \\
\hline$\%$ & العدد & & $\%$ & العدد & & \\
\hline & & & 8.9 & 15 & المجمع السكني & 25 \\
\hline 100 & 154 & المجموع الكلي & 100 & 167 & المجموع الكلي & \\
\hline
\end{tabular}

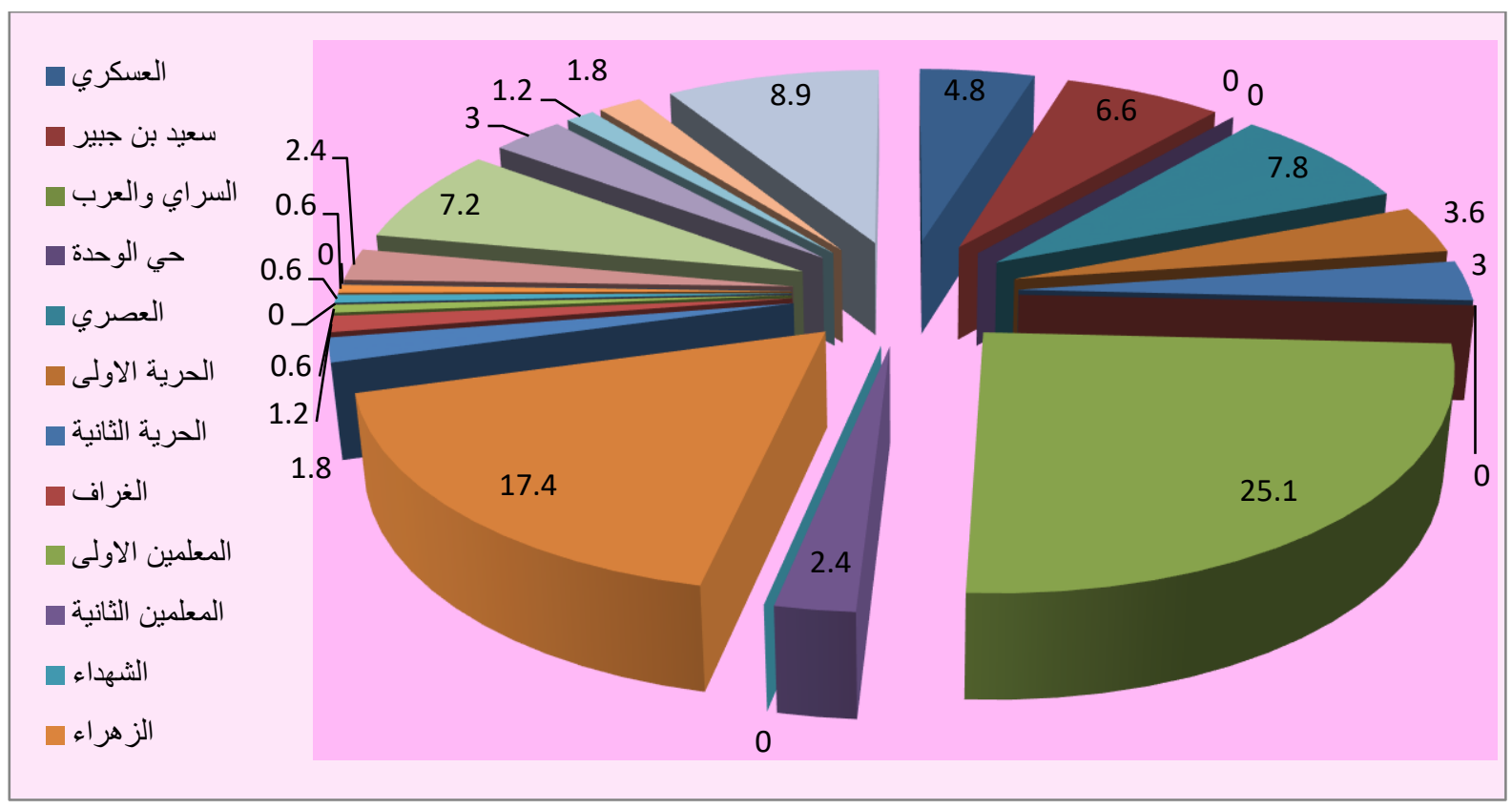

شكل (3): اتجاهات الأسر الر اغبة في الانتقال السكني مستقبلاً في مدينة الحي. المصدر : جدول (2).

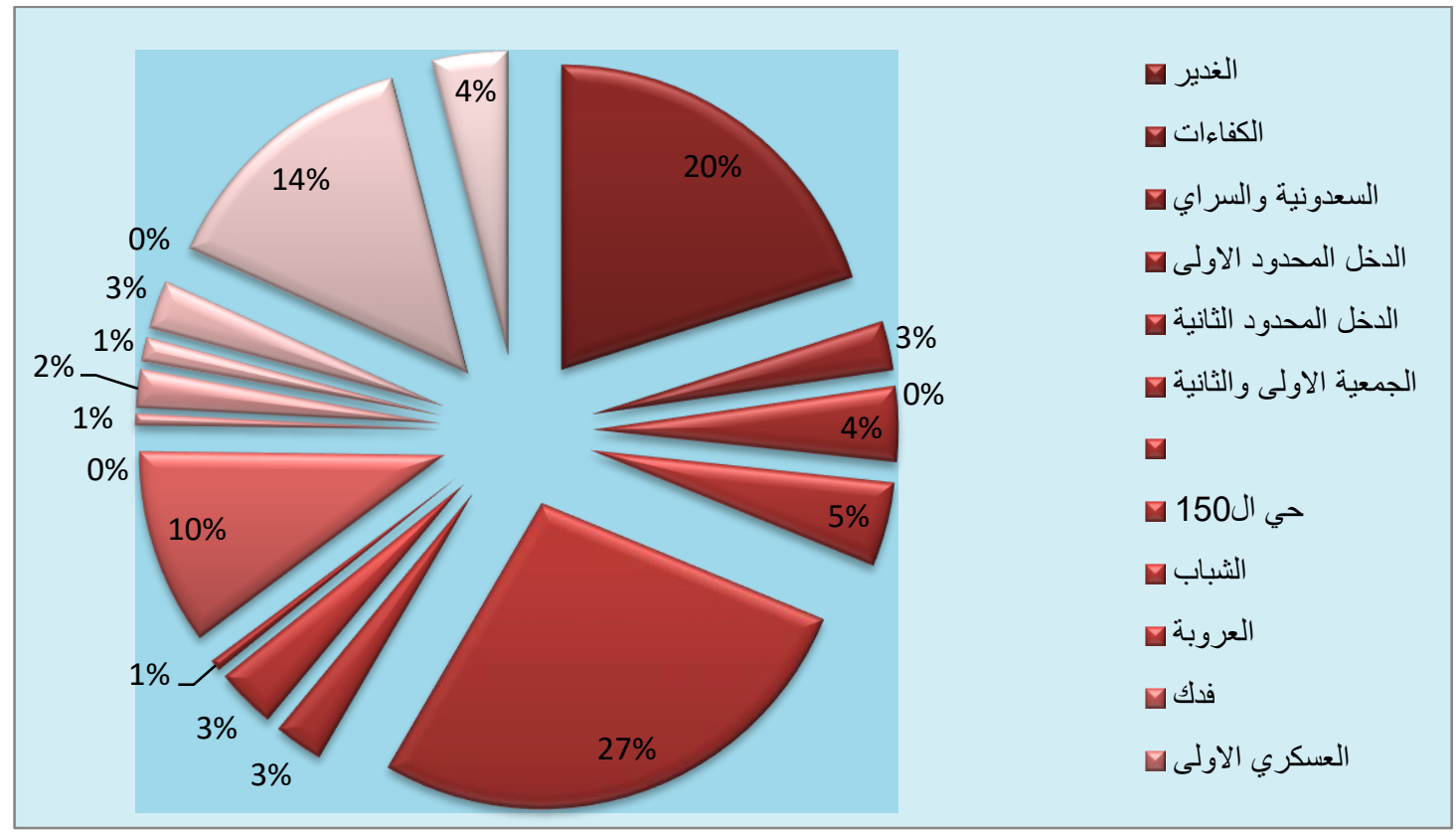

شكل:4:اتجاهات الأسر الر اغبة في الانتقال السكني مستقبلاً في مدينة العزيزية. المصدر : جدول (2). 


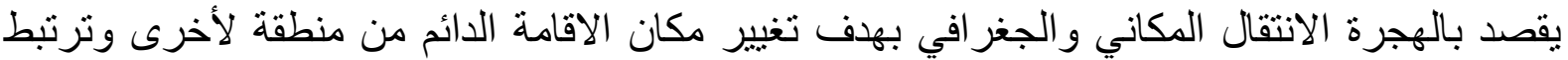

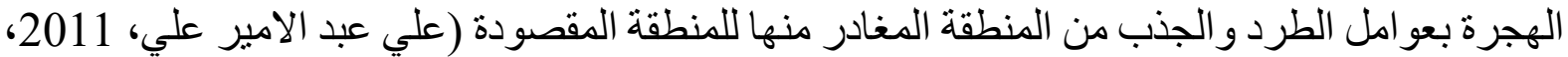
ص302)][11] تؤدي الهجرة الى زيادة حجم السكان فتعمل على زيادة الطلب للأر اضي و الوحدات السيكة السكنية ل الأجل الاستقر ار و العيش فيها.

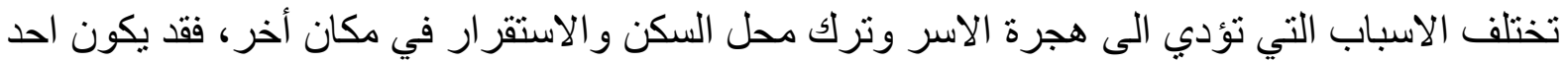
اسباب الهجرة اقتصادي للبحث عن عمل [12], اذ اظهرت الإن الدراسة الميدانية بأن عدد الأسر. جدول (3): الاسر المهاجرة الى مدينتي الحي والعزيزية. المصدر: استمارة استيان، المحور الرابع الخاص بتغيير محل

\begin{tabular}{|c|c|c|c|c|c|c|}
\hline & & \multicolumn{5}{|c|}{ السكن، السؤال الثاني } \\
\hline$\%$ & المجموع & $\%$ & اخرى افظات & $\%$ & محافظة & \\
\hline 100 & 72 & 54.2 & 39 & 45.8 & 33 & الحي - ل الحي \\
\hline 100 & 83 & 54 & 45 & 46 & 38 & العزيزية \\
\hline
\end{tabular}

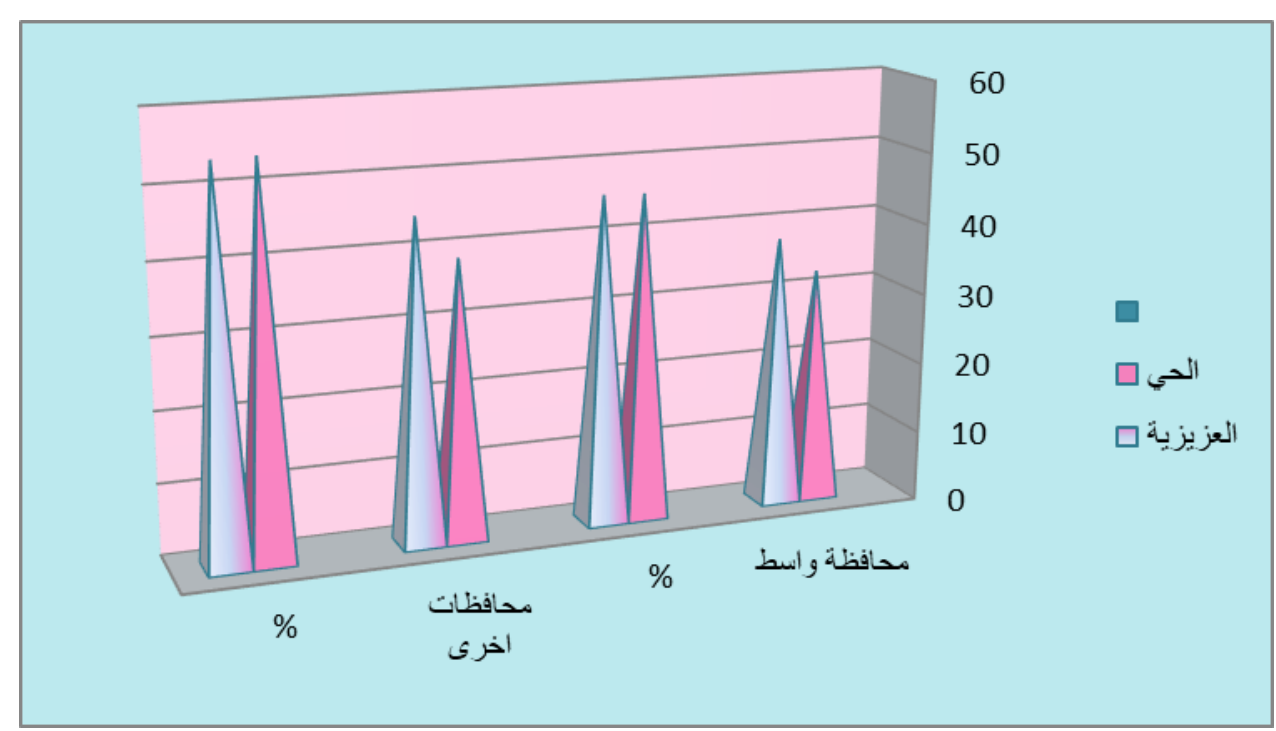

شكل(5): الاسر المهاجرة الى مدينتي الحي والعزيزية. الدصدر: جدول (3).

المهاجرة الى مدينة الحي بلغت (72) أسرة شكلت نسبة (19\%) من مجموع الأسر المستجوبة ميدانباً، منها

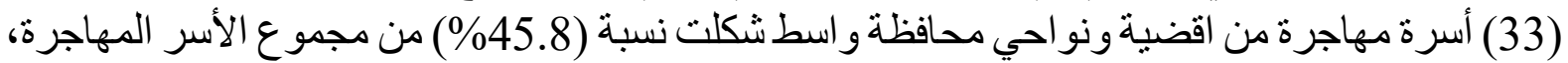

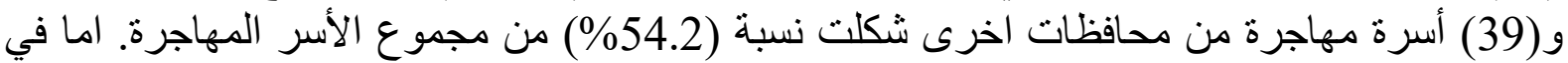

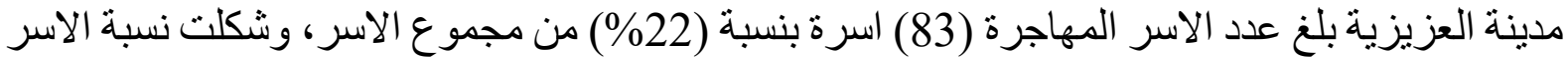

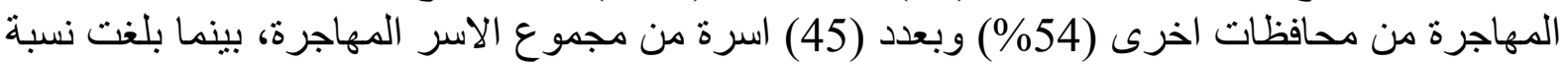
الاسر المهاجرة من اقضية ونو احي محافظة واسط (46\%) وبعة (45) وبعدد (38) اسرة من مجموع الاسر المهاجرة الهرة.

تجزئة الوحدة السكنية

تنتشر هذه الظاهرة في اغلب المدن العر اقية ويقصد بها اعادة تقسيم الارض السكنية الى قطع اصغر لحاجة الحئ

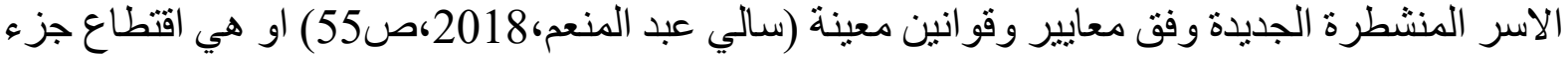

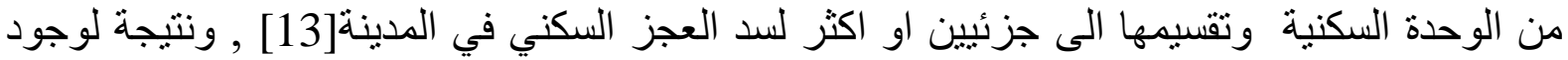

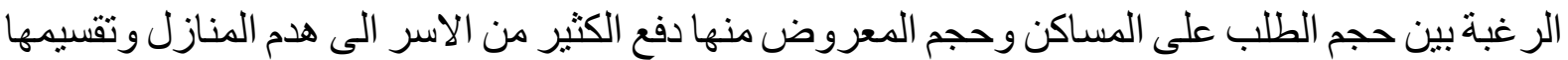

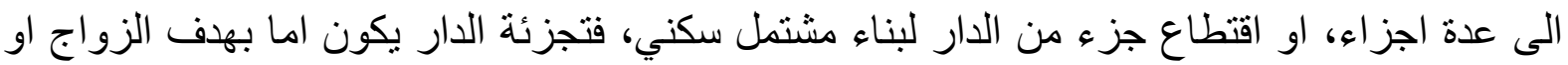

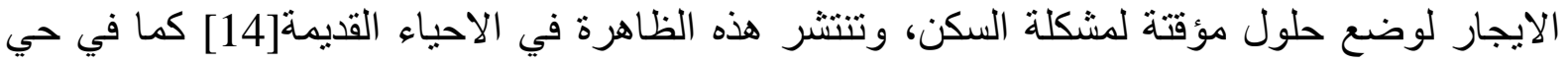


العرب، الجديدة، السر اي، ودعت عدة اسباب اقتصادية واجتماعية تتمثل بارتفاع تكاليف الوحدات السكنية

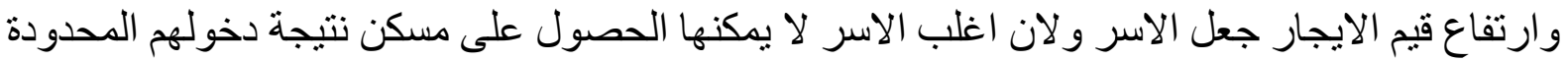

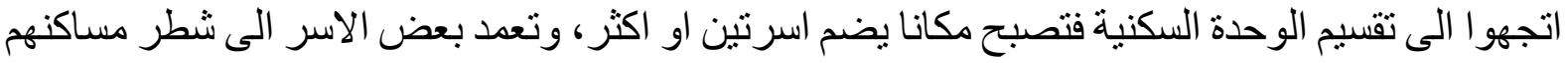

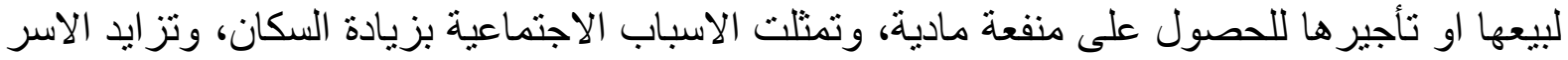
و الانشطار ات العائليةز ادت من حجم الطلب على المساكن مما اجبر الاسر على تجزئة ملئة مساكنهم. من نتائج المسح الميداني تبين ان الوحدات المجزئة بلغت (11\%) من عينة المساكن الممسوحة في مدينة

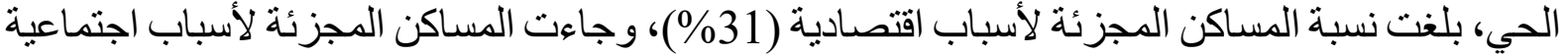

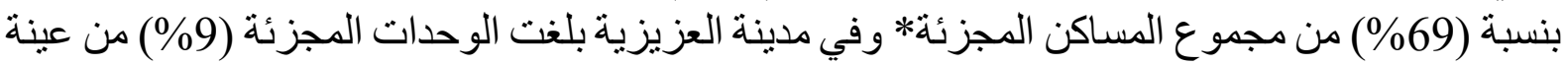

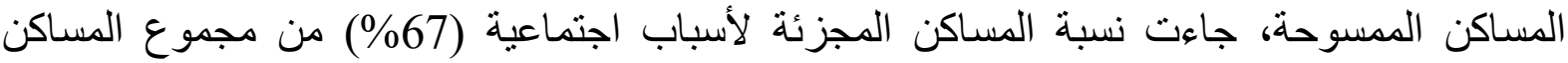
المجزئة، وبلغت نسبة المساكن المجزئة لأسباب اقتصادية (33\%) من مجموع المساكن المجزئة المبئة، من سلبيات تجزئة المساكن زيادة التلوث البيئي والضوضئة ونئئي نتيجة ارتفاع اعداد سكان الحي وتز احم الابنية، تشوه وجه المدينة الحضري.

تبين من خلال الدراسة الميدانية ان رغبة الاسر بالانشطار في مدينة الحي بلغت (85) اسرة وبنسبة (22.7\%) من مجموع عينة الدر اسة، وشكلت نسبة الاسر التي تر غب بتجزئة الونة الوحدة السكنية في مدينة العزيزية (19\%) وبعدد (72) اسرة من مجموع الاسر، وتقف جمله من العو امل خلف ظاهرة تجزئة

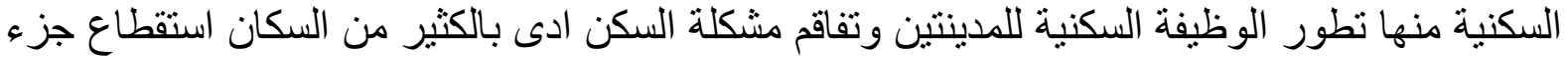

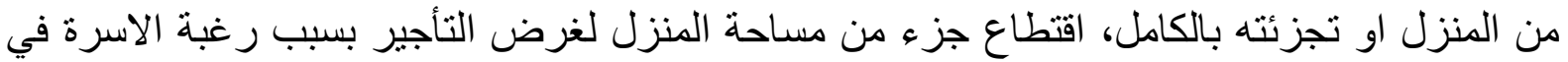

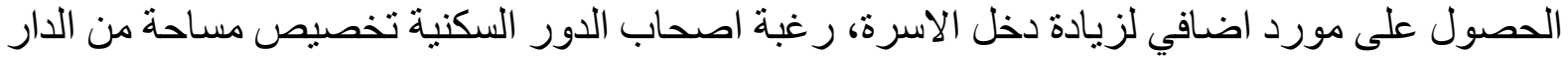

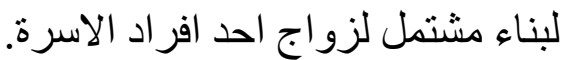

\section{تحوير الوحدات السكنية}

تعني التغير ات التي تحدث على بنية الوحدة السكنية الخارجية و الداخلية وتجري عملية التحوير لعدة اسباب

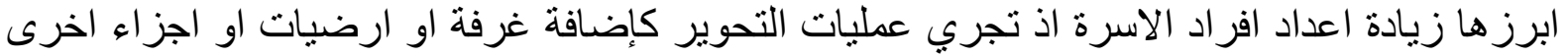

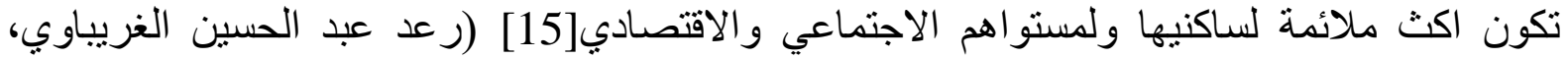

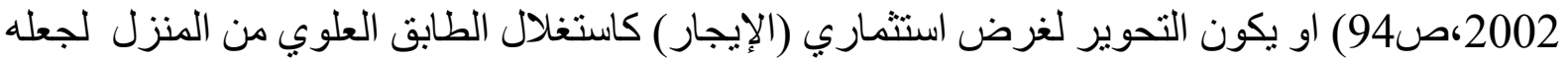

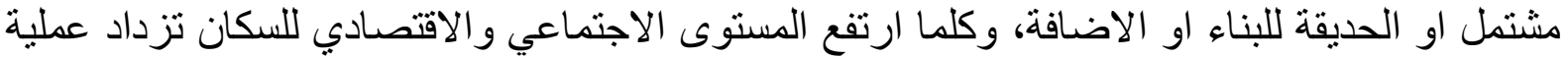

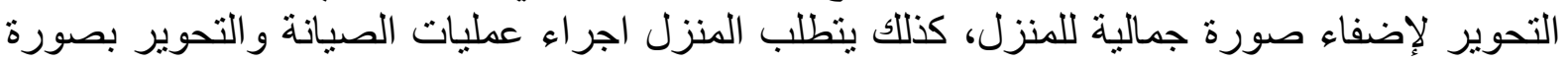

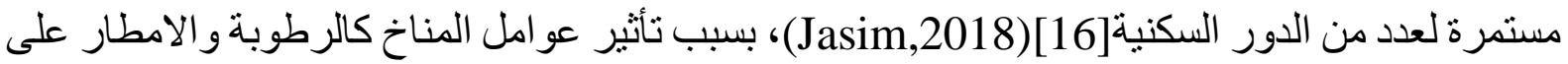

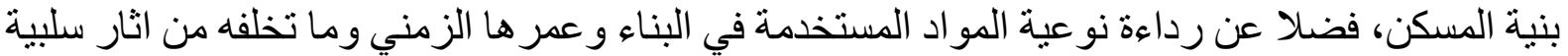

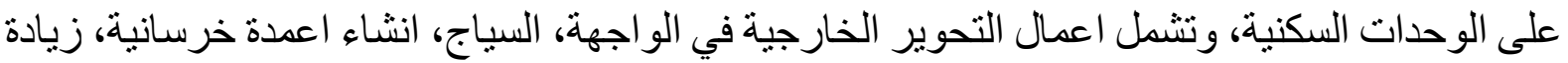

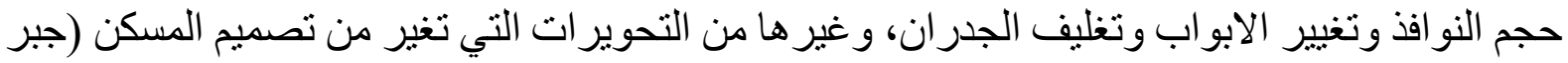

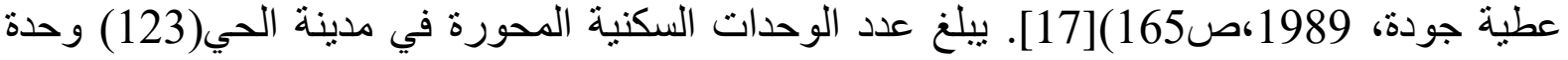

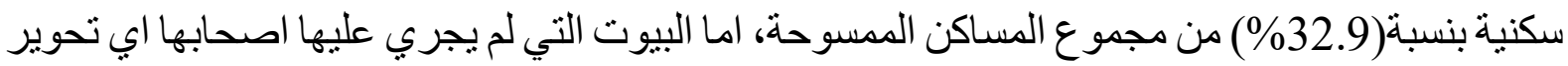
بلغ عددها (251) بنسبة (67.7\%) من مجموع البيوت التي تم مسحها ميدانبا، وفي مدينة العزيزية بلغ عدد البيوت المحورة (134) بيتا بنسبة (25.8\%) من مجموع البيوت التي تم مسحها ميدانيا، اما البيوت

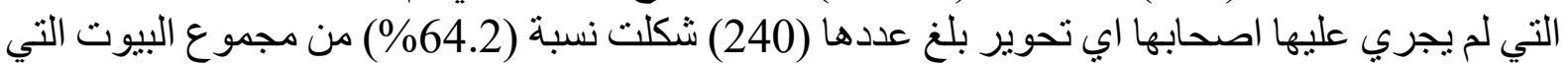
تم مسحها ميدانيا.

توجد اسباب عديدة تهدف الى اجر اء عملية التحوير لتحقيق الكفاية الوظيفة للمسكن، وذلك بزيادة عدد الغرف لاستيعاب عدد افراد الاسرة، كما يحسن اصحاب هذه البيوت الى تحسين وضعهم الاقتصادي 
باستثمار البيوت ذات المو اقع التجارية وتحوير جزء منها كمحلات تجارية او مخازن لزيادة دخل الاسرة.

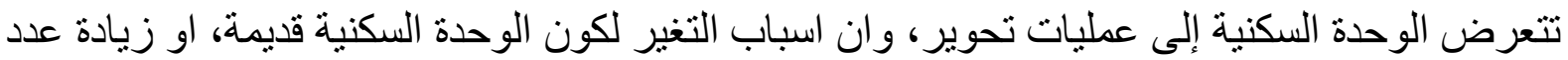

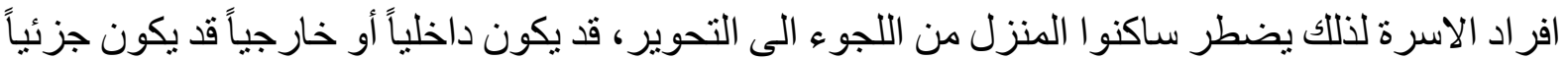

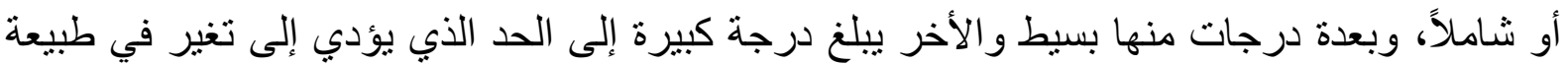

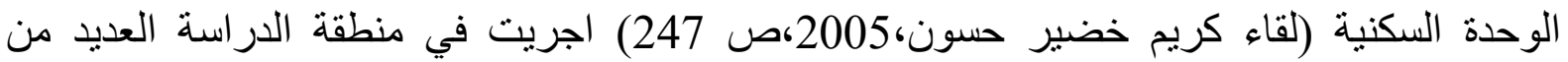

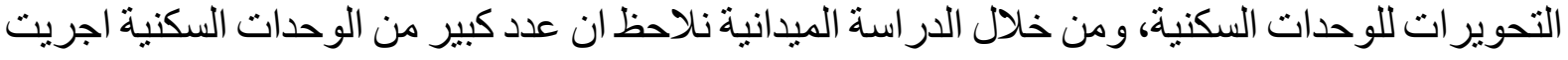

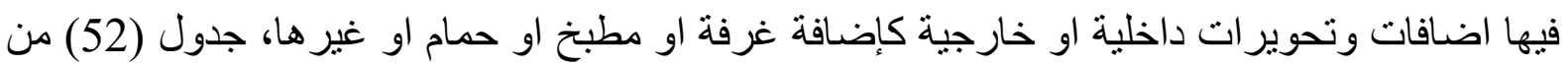

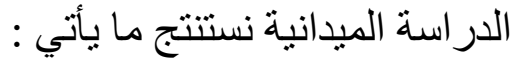

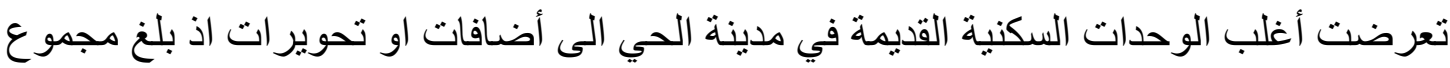

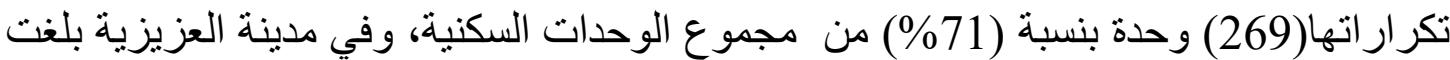
التحوير ات في الوحدات السكنية (257) وحدة سكنية وشكلت نسبة (68.7 من \%).

جدول (4): عدد الوحدات السكنية المحورة في مدينتي الحي و العزيزية. المصدر : الدر اسة الميدانية، استمارة الاستبيان، المحور الر ابع، السؤال(5). المئلة.

\begin{tabular}{|c|c|c|c|c|c|c|c|}
\hline \multicolumn{4}{|c|}{ مدينة العزيزية } & \multicolumn{4}{|c|}{ مدينة الحي } \\
\hline حجم العينة & خارجير & تحوير داخلي & غير محورة & حجم العينة & تارجي & تحوير داخلي & غير محورة \\
\hline 374 & 81 & 176 & 117 & 374 & 84 & 185 & 105 \\
\hline 100 & 21.6 & 47.1 & 31.3 & 100 & 22.5 & 49.4 & 28.1 \\
\hline
\end{tabular}

تشثل التحويرات التي أجريت في داخل الوحدات السكنية بناء غرفة جديدة في الطابق العلوي

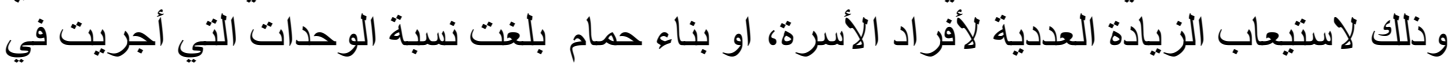

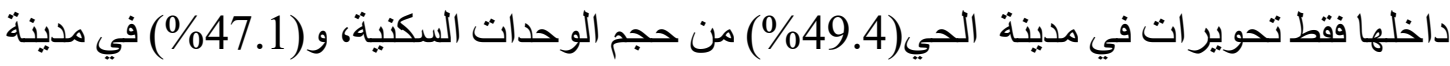

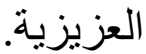

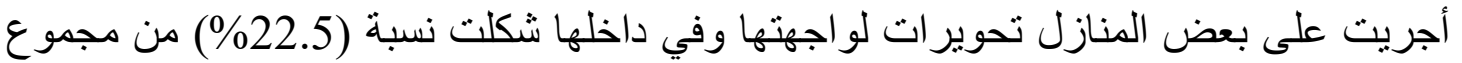
الوحدات السكنية في مدينة الحي، في حين بلغت نسبة الوبة الوحدات المحورة في مدينة العزيزية (21.6\%) من مجموع العينة. بلغت نسبة عدد الوحدات التي لم تجري أي أضافة او تحوير في وحداتها السكنية(28.1\%) في في الحي، و (31.3\%) في العزيزية.

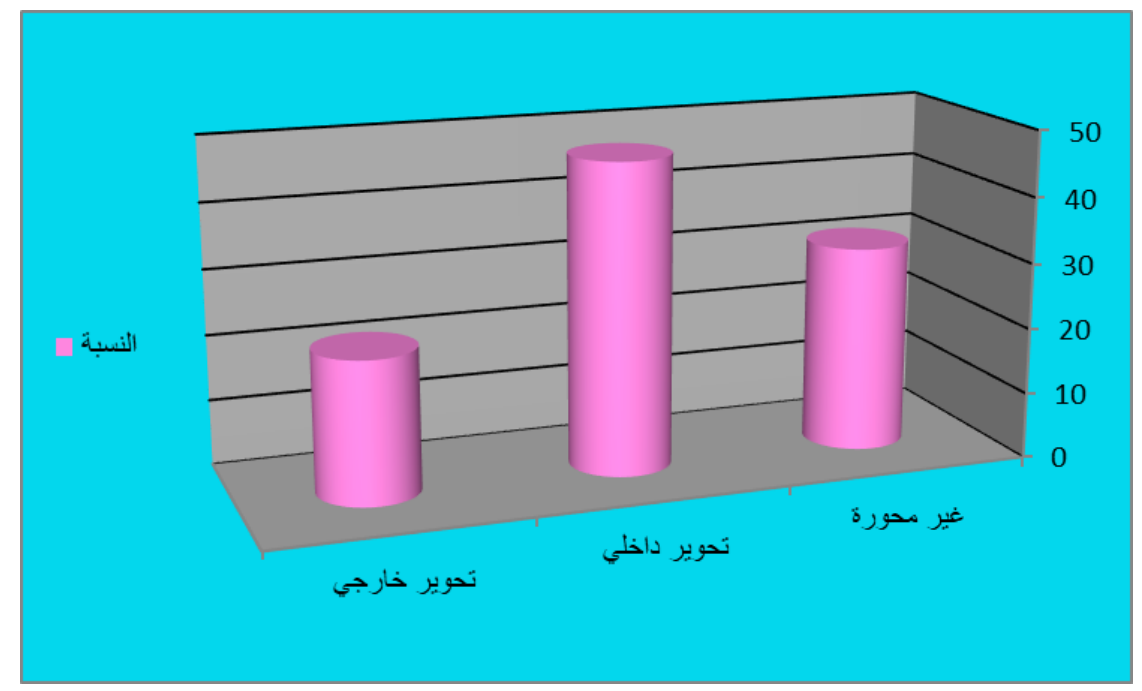

شكل 6: نسبة عدد الوحدات المحورة في مدينة العزيزية. المصدر: عمل الباحثة بالاعتماد على بيانات جدول 


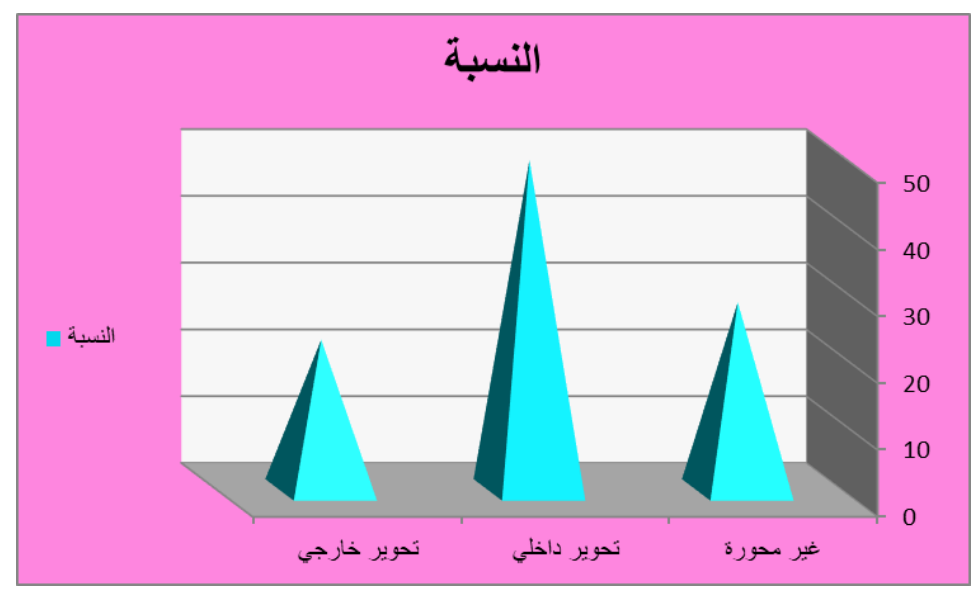

شكل .7: نسبة عدد الوحدات المحورة في مدينة الحي. المصدر: عمل الباحثة بالاعتماد على بيانات جدول (4).

الاستنتاجات

ظهر في هذا البحث العديد من النتائج اتضح من خلالها:

1. للعو امل الاجتماعية دور مهم في عملية الحر الك السكني بسبب الزواج وتغير حجم الاسرة.

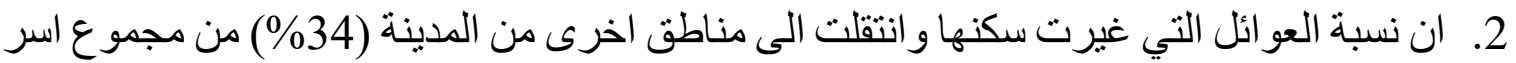
عينة الدر اسة في مدينة العزيزية.

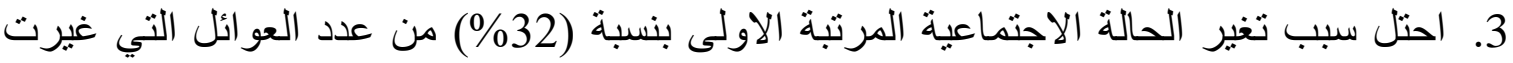

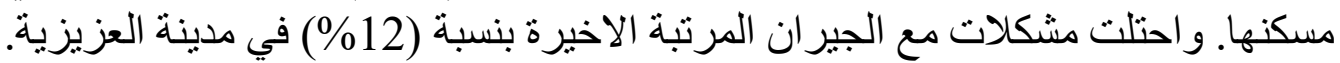
4. شكلت ظاهرة الحر الك السكني نسبة (28\%) من مجموع اسر عينة الدر اسة في مدينة الحي.

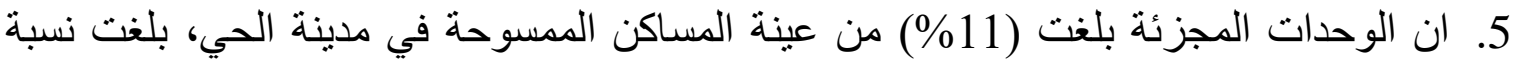

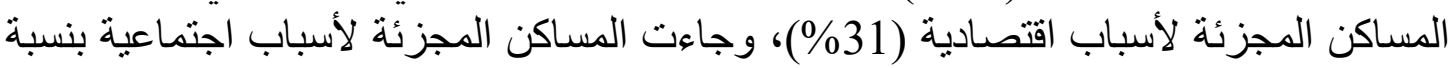
(2\%99) من مجموع المساكن المجزئة.

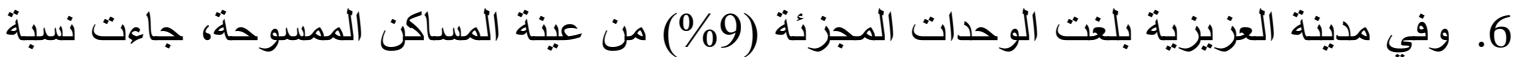

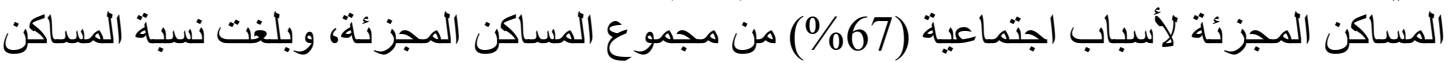
المجزئة لأسباب اقتصادية (33\%) من مجموع المساكن المجزئة.

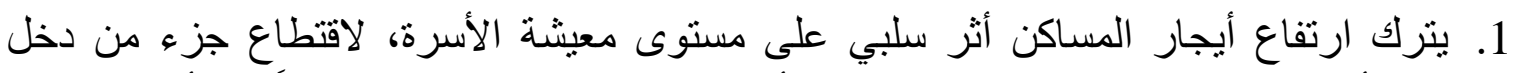

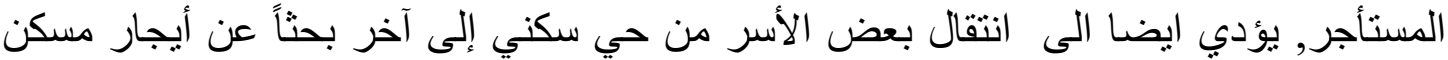
رخيص، لذلك يجب الحد من ارتفاع ايجار المسكن. 2. تقديم در اسة شاملة عن واقع الاحياء السكنية القديمة وتطوير ها و الاهتمام بها وتحسين الخدمات التهات

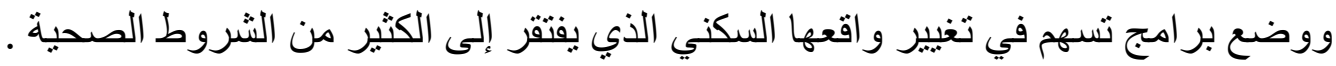
3. توفير قطع الأراضي السكنية وتوزيعها على المواطنين، التي تساهم بها بلدية مدينتي الحي

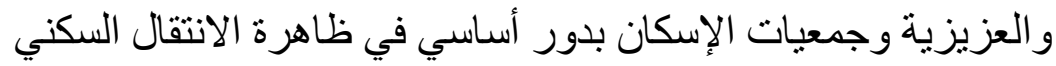




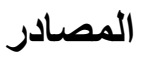

1. H. S. Farhan, T. Mutas, "Digital Era Influence on Neighbourhood Planning," I O P Conf. Sci. Mater., 2021, doi: 10.1088/1757-899X/1058/1/012042.

2. S. L. Farhan, V. S. Akef, and Z. Nasar, "Revitalizing the historical center of Al-Najaf city in Iraq: learning from the British conservation experiences," J. Cult. Herit. Manag. Sustain. Dev., vol. ahead-of-p, no. ahead-of-print, Jan. 2021, doi: 10.1108/JCHMSD-01-2020-0002.

3. A. A. Al-Mayahi, "A comparative study of the functional region of the cities of Kut and Hilla," p. 75825, 2021.

4. S. L. Farhan, "Sustainable neighborhood Comparative Analysis of Al Kut Neighborhoods Sustainable neighborhood Comparative Analysis of Al Kut Neighborhoods," no. December, pp. 302-317, 2018.

5. S. lafta farhan, "Deterioration in the centers of historic towns The case study: the residential environment for the ancient of Kut city," iraqi J. Archit. Plan., vol. 10, no. 3, pp. 128-148, 2014, [Online]. Available: https://arcp.iraqjournals.com/article_159641.html.

6. I. A. Jasim, H. M. Hasan, S. L. Farhan, and K. H. Bahat, "Evaluating the urban structure of Al-Kut city according to sustainability," \{IOP $\}$ Conf. Ser. Earth Environ. Sci., vol. 779, no. 1, p. 12021, Jun. 2021, doi: 10.1088/1755-1315/779/1/012021.

7. I. Abbass Jasim, S. Lafta Farhan, and S. AL-MAMOORI, "Smart Government: Analysis of Shift Methods in Municipal Services Delivery: The Study Area: Al-Kut - Iraq," J. Univ. Kerbala, vol. 15, no. 3, p. 2017, 2017.

8. H. S. O. Adelphi, S. L. Farhan, and A. H. Haitham, "Threshold of Urban Sustainability within the Traditional Cities : Traditional Alnajaf city as a case study," IOP Conf. Ser. Mater. Sci. Eng., vol. 1058 (2021, 2021, doi: 10.1088/1757-899X/1058/1/012055.

9. S. L. Farhan, H. I. Alyasari, H. H. Samir, S. L. Zubaidi, and K. S. Hashim, "Conservation Approach as an Architectural Instrument to reviving Historical Cities; technical analysis for multi international cases," IOP Conf. Ser. Mater. Sci. Eng., vol. 1058, no. 1, p. 12071, 2021, doi: 10.1088/1757-899x/1058/1/012071.

10. H. S. O. Adelphi, S. L. Farhan, and H. A. H. Alshamari, "The Threshold of Urban Sustainability within the Traditional Cities: Traditional Alnajaf city as a case study," $\{$ IOP $\}$ Conf. Ser. Mater. Sci. Eng., vol. 1058, no. 1, p. 12055, Feb. 2021, doi: 10.1088/1757899x/1058/1/012055.

11. S. L. Farhan, H. I. Alyasari, V. S. Akef, S. L. Zubaidi, and K. S. Hashim, "Analysing the Transformed Urban Patterns of Al-Najaf Historical Center: Urgent Issues and Possible Solutions," IOP Conf. Ser. Mater. Sci. Eng., vol. 1058, no. 1, p. 12052, 2021, doi: 10.1088/1757-899x/1058/1/012052.

12. S. L. Farhan, H. H. Samir, and H. S. Adelphi, "Urban changes and its impact on the tangible and intangible heritage of City's Centre: Najaf City as a Case Study," IOP Conf. Ser. Mater. Sci. Eng., vol. 1058, no. 1, p. 12070, 2021, doi: 10.1088/1757-899x/1058/1/012070.

13. Z. A. 2 ; Farhan, Sabeeh Lafta 1 ; Nasar, "Urban identity in the holy cities of Iraq: Analysis trends of architectural designers in the city of Karbala," J. Urban Regen. Renew., vol. 14 Number, no. 2020, pp. 210-222(13), 2020.

14. S. Farhan and M. G. Abdelmonem, "Navigating the socio-spatial and planning conditions of traditional public spaces in Iraq's holy cities," in Traditional Dwellings and Settlements Review, Oct. 2018, vol. 30, no. 1, p. 81, doi: 10.2307/26877469. 
15. S. L. Farhan, "Effect of New Urban Transformations at Townscape of Historical Cities Urban Study of Alnajaf Hist,” J. Eng., vol. 23, no. December, pp. 1-20, 2018.

16. I. A. Jasim, S. L. Farhan, and H. M. Hasan, "The Impact of Transit on Sustainable Urban Form,” IOP Conf. Ser. Mater. Sci. Eng., vol. 1058, no. 1, p. 12049, 2021, doi: 10.1088/1757899x/1058/1/012049.

17. I. A. Jasim, S. L. Farhan, and H. M. Hasan, "Ways to Activate Urban Transport to Achieve Urban Sustainability," IOP Conf. Ser. Mater. Sci. Eng., vol. 1090, no. 1, p. 012034, 2021, doi: 10.1088/1757-899x/1090/1/012034. 